\title{
Risk analysis of restrictive factors for fast-track hip arthroplasty - a retrospective study of 1138 patients
}

\author{
Florian Radetzki, Tina Körber, David Wohlrab, Karl Stefan Delank \\ From the Department of Orthopaedics, Trauma and Reconstructive Surgery, Martin Luther University Halle-Wittenberg, \\ Halle (Saale), Germany
}

Fast track programs have been introduced to reduce perioperative complication rates and to quickly reintegrate the patient into everyday life. The aim of this retrospective case-control study was to identify patient characteristics and patient-independent factors that influence fast track programs in hip arthroplasty. A total of 1138 patients were examined. A hospital stay of more than seven days was used to define the case group. In addition to the causes for the longer hospitalisation, age, sex, BMI, chronic nicotine and alcohol abuse, ASA score, surgical duration, anaemia and blood transfusion as well as concomitant diseases were assessed. The statistical analysis included two-sample t-test, chi-square test and logistic regression analyses. An $95 \%$ confidence interval was calculated $(p<0.05) .16 .9 \%$ of patients could not leave the hospital on the seventh day. The main causes were delayed wound healing $(69.4 \%)$, increased CRP $(43.0 \%>100 \mathrm{mg} / \mathrm{l})$, and internal complications $(19.7 \%)$. At a mean of $69.2 \pm 10.7$ years, the age of the case group was significantly higher than that of the control group, which had a mean of $63.3 \pm 10.3$ years $(p<0.001)$. Cardiac comorbidities $(p<0.001)$, BMI $(p=0.023)$, and alcohol consumption $(p<0.001)$ increased the risk for longer hospitalisation. Significant patient-independent factors were duration of the surgery $(p<0.001)$ and transfusion $(p<0.001)$. Successful application of fast-track hip arthroplasty is possible for every patient. However, longer hospitalisation and delayed discharge must be taken into account for patients with advanced age, cardiac comorbidities, alcohol consumption, and high BMI.

No benefits or funds were received in support of this study. None of the authors have a conflict of interest.
Keywords fast track program; hip arthroplasty; restrictive factors.

\section{INTRODUCTION}

The implantation of a total hip endoprosthesis is one of the most common standard surgical procedures today. To reduce perioperative complication rates and to quickly reintegrate the patient into everyday life, so-called fast-track programs have been introduced. The goal of interdisciplinary evidencebased treatment paths is rapid convalescence of the patient. Because of the shortened inpatient stays

Florian Radetzki ${ }^{1,2}$, PD Dr

Tina Körber ${ }^{3}$, Dr

David Wohlrab ${ }^{4}$, Prof

- Karl Stefan Delank ${ }^{4}$, Prof

'Dessau Municipal Hospital, Dessau-Roßlau, Germany.

${ }^{2}$ Brandenburg Medical School Theodor Fontane, Neuruppin, Germany.

${ }^{3}$ Department of Internal Medicine, KRH Klinikum Nordstadt, Hannover, Germany.

${ }^{4}$ Martin Luther University Halle-Wittenberg, Department of Orthopaedics, Trauma and Reconstructive Surgery, Halle (Saale), Germany.

Correspondence : PD Dr. med. habil. Florian Radetzki, Dessau Municipal Hospital, Auenweg 38, 06847 DessauRoßlau, Germany. Phone: 0340 501-3600.

Email : florian.radetzki@gmx.de

- 2021, Acta Orthopædica Belgica.

Acta Orthopædica Belgica, Vol. 87 - 4 - 2021 
combined with a significant cost reduction, fasttrack programs are also important for the general population from an economic point of view (1-3). Important components of fast-track programs are successful pain therapy and rapid postoperative mobilisation of the patient. Daily extensive physiotherapeutic treatment is crucial for a good postoperative result (4). Therefore, it is important that physiotherapeutic exercises start early and intensively after the operation, which counteracts a reduction in muscle strength and reduces the occurrence of thromboembolic events $(5,6)$. Special rehabilitation programs that make inpatient discharge possible more quickly decrease mortality rates and inpatient resumption and revision operations $(6,7)$. The average inpatient residence time as part of hip total prosthesis implantation was 11.8 days, and there was a decreasing trend in Germany in 2014 (8). This trend towards shorter stays will continue in the future by further optimising the schedules with even faster convalescence and reintegration into everyday life. The defined treatment programs would be applicable in principle to all patient groups without exclusion. As part of the interdisciplinary fast-track program for the implantation of a hip total endoprosthesis at the University Hospital Halle, rapid convalescence is sought through early mobilisation and multimodal support. Patients should be able to be discharged into further treatment on the seventh day of inpatient care. However, this requirement was not feasible for all patients. Early identification of these patients, who require a longer stay with more intensive therapeutic measures, can contribute to the improvement of future care and rehabilitation planning. The aim of this retrospective case-control study was to identify patient characteristics and selected patient-independent factors that may be associated with a longer period of residence within the fast track program. In addition, the reasons for discharge and the frequency of complications were evaluated.

\section{MATERIALS AND METHODS}

In the period from October 2007 to May 2013, in the University Hospital Halle (Saale), Germany, 1138 patients had undergone primary total hip replacement surgery. Without exclusion criteria, each patient was followed for the procedure by the internal hospital fast-track program. This process included preoperative patient information and education, effective interdisciplinary pain treatment, early mobilisation within a few hours after the operation, intensive daily physiotherapy and early discharge, no later than the 7th day of hospitalization. All surgeries were performed by three welltrained surgeons. The operative minimally invasive procedure was the same for all patients. The main objective of this case-control study was the number of days during the stationary stay. For the case group, a stay of more than seven days was defined. The exclusion criterion was a direct transfer of the inpatient follow-up treatment after 7 days for organizational reasons. Each patient was compared to a patient with a maximum stay of 7 days who underwent surgery on the same day and by the same surgeon. These patients formed the control group. In addition to the causes for the longer residence time, metadata (age, sex, and BMI), chronic nicotine and alcohol abuse, ASA score, surgical duration, anaemia and blood transfusion, as well as concomitant diseases of the patients, were determined from the medical records. The statistical analysis was performed with SPSS version 22 (IBM Corp., Armonk, NY, USA) and included a twosample t-test and chi-square test based on Pearson and logistic regression analysis. A confidence interval of 95\% was assumed (significance level $\mathrm{p}$ $<0.05)$.

\section{RESULTS}

The analysis of 1138 patients revealed that $16.9 \%$ could not leave the hospital on the seventh day after surgery. This finding led to the formation of a case and control group with 193 patients each. The gender distribution in both groups was identical (88 men, 45.6\% each; and 105 women, 54.4\% each). Reasons for the nondischarge of the patient on the seventh inpatient day are shown in Figure 1. The three most common causes of extended stay were delayed wound healing (69.4\%) with prolonged secretion or wound edge dehiscence beyond day 7 after surgery, increased CRP $(43.0 \%>100 \mathrm{mg} / \mathrm{l})$, 


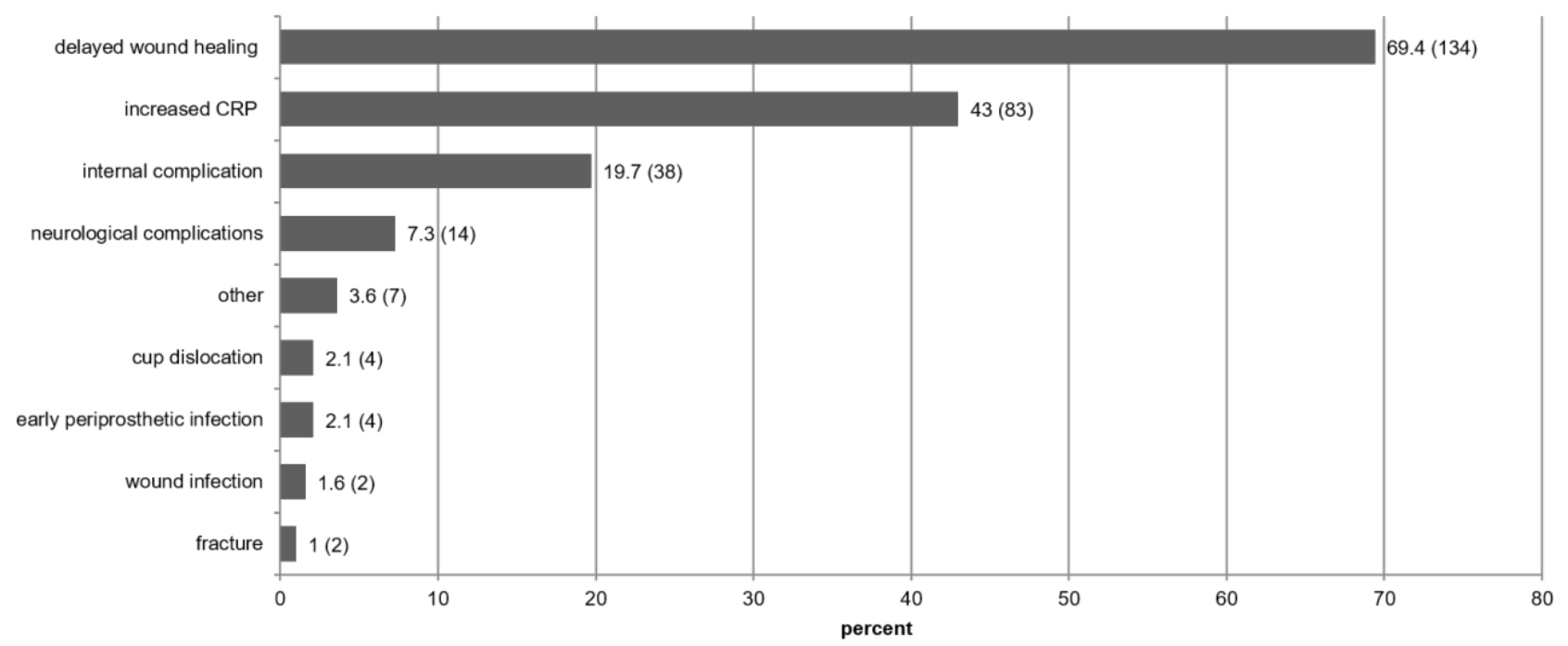

Figure 1. - Reasons against dismissal in percent (number of patients)

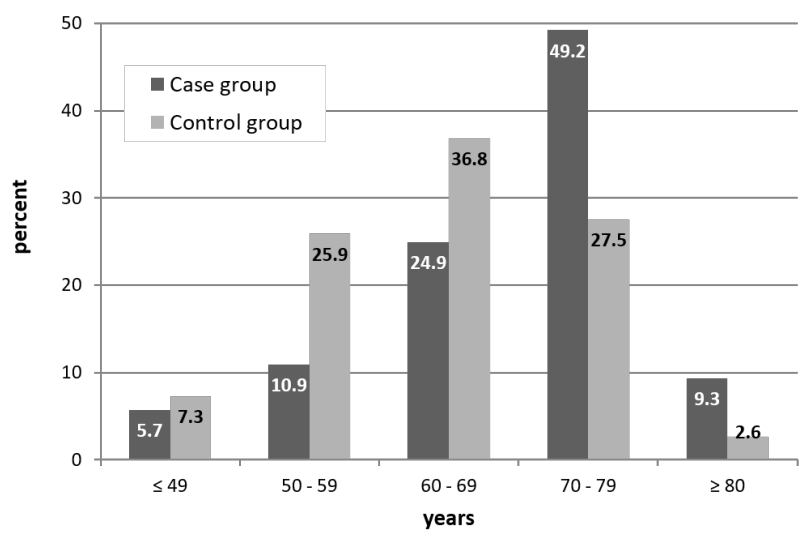

Figure 2. - Age distribution of the case and control group in percent

and internal complications (19.7\%). There were certain significant differences between the case and control groups, according to patient characteristics and patient-independent factors. At $69.2 \pm 10.7$ years, the age of the case group was significantly higher than that of the control group at $63.3 \pm 10.3$ years $(p<0.001)$. In particular, the division into age groups showed that at the time of the intervention, almost half of the patients $(49.2 \%)$ in the case group were between 70 and 79 years old, while only $27.5 \%$ were in the control group. Among those over 80 years of age, the proportion was $9.3 \%$ in the case group and only $2.6 \%$ in the control group. In contrast, both the 50-59 and 60-69 age groups had significantly higher proportions of patients in the control group (Figure 2). Patients with cardiac diseases were more likely to be discharged on the seventh day of inpatient care than patients without cardiac secondary diagnoses (case group 39.9\%, control group $14 \%, \mathrm{p}<0.001)$. Smoking did not play a significant role in hospitalisation. A total of $13.5 \%$ of patients in the case group had, and There was no significant difference in the proportion of patients with chronic nicotine abuse between the case group and the control group (13.5\% vs. $13.0 \%$, $\mathrm{p}=0.881$ ). In contrast, patients with chronic alcohol consumption had the most significantly increased odds of extended inpatient stays $(\mathrm{p}<0.001)$. Further significant patient-independent differences between the groups were apparent in the duration of the surgery (case group $90.8 \pm 40.3 \mathrm{~min}$ vs control group $79.2 \pm 23.1 \mathrm{~min}, \mathrm{p}<0.001)$ and need for transfusion (case group $67.9 \%$ vs control group $42.5 \%, \mathrm{p}<0.001)$.

The results of the logistic regression analysis are shown in Table I. Ten variables were used to perform logistic regression analysis. There was no significantly increased risk for prolonged inpatient stay for pulmonary diseases, arterial hypertension, gout or osteoporosis. In contrast, each additional age year increased the risk for a longer hospitalisation by 1.040 times. Similarly, there was an increase in risk to 1.066 times for every one unit increase 
Table I. - Results of the logistic regression analysis

\begin{tabular}{|l|c|c|}
\hline \multicolumn{2}{|c}{ p } & $\begin{array}{c}\text { Odds ratio, confidence } \\
\text { interval of 95\% }\end{array}$ \\
\hline Age & 0.003 & $1.040 ;$ CI 95\%: 1.013-1.066 \\
\hline BMI & 0.023 & $1.066 ;$ CI 95\%: 1.009-1.126 \\
\hline $\begin{array}{l}\text { Chronic alcohol } \\
\text { consumption }\end{array}$ & 0.001 & $2.939 ;$ CI 95\%: 1.560-5.538 \\
\hline Surgery time & 0.021 & $1.010 ;$ CI 95\%: 1.002-1.019 \\
\hline Transfusion & 0.001 & $2.382 ;$ CI 95\%: 1.458-3.892 \\
\hline Arterial hypertension & 0.989 & $0.996 ;$ CI 95\%: 0.586-1.693 \\
\hline Cardiac diseases & 0.001 & $2.559 ;$ CI 95\%: 1.466-4.468 \\
\hline Gout & 0.114 & $1.786 ;$ CI 95\%: 0.871-3.665 \\
\hline Pulmonary diseases & 0.449 & $1.351 ;$ CI 95\%: 0.620-2.947 \\
\hline Osteoporosis & 0.058 & $2.298 ;$ CI 95\%: 0.973-5.426 \\
\hline
\end{tabular}

in BMI. The same applied to the duration of the operation; an extension of one minute increased the patient's risk of an extended inpatient stay by 1.010 times. Patients with positive chronic alcohol consumption had the most significant increase in risk for extended stays. The risk of prolonged inpatient stay with existing alcohol consumption was 2.939 times higher than the risk of patients without it. The influence of the transfusion of erythrocyte concentrates was also highly significant. Requiring transfusion increased the probability of patients having an extended stay by 2.382 -fold. The analysis of secondary diseases showed that only cardiac comorbidities had significant relevance. In patients with cardiac diseases, there was a 2.559 times higher risk of discharge on the seventh day than in patients without a cardiac diagnosis.

\section{DISCUSSION}

Since the beginning of joint prosthetics, the procedure of total hip arthroplasty implantation has been constantly being developed and is experiencing further optimisation. Today, this operation is not only one of the most common interventions in Germany but is also a procedure with the greatest long-term improvement in quality of life for the patient. The holistic perioperative management of fast-track programs enables decreased in postoperative complication rates while increasing patient satisfaction (9-11). However, not all patients can be included in these programs, and universal rapid convalescence cannot be expected. Nearly $17 \%$ of all patients failed to be discharged from hospital by 7 days in this study. The most common reason for nondischarge was delayed wound healing, followed by increased inflammation values and internal complications. Restrictive factors for fast-track hip arthroplasty were patient-specific and patient-independent. The statistical analysis showed a significant difference in age between the case and control groups. Husted and Hartog have found a similar result in their regression analyses $(12,13)$. Patients over 80 years of age, in particular, often need a longer inpatient stay until they can be released to subsequent rehabilitation (14). There are a number of studies that show that increased age is associated with increased postoperative complication rates as well as prolonged hospitalisation (15-18). However, in contrast, several groups of authors have also shown that the decisive factor influencing postoperative outcome, and thus the inpatient length of stay, is not only age per se but also the number of comorbidities at the time of surgery $(19,20)$. In this work, comorbidities were examined according to their sole effect on the duration of inpatient residence, whereby only cardiac diseases showed a significant influence in the regression analysis. In a large systemic literature review, it was demonstrated that it is not the individual disease itself but rather the sum and special combinations of various diagnoses at the time of the operation that have a decisive influence on the duration of inpatient residence $(21,22)$. Another patient-specific factor is the patient's BMI, which had a significant impact on the stationary stay. Patients with significantly increased BMI values, in particular, need a longer period of inpatient care until the discharge conditions are reached $(16,23,24)$. In fast track hip arthroplasty, postoperative mobilization is more difficult because of the increased body weight in combination with decreased muscle strength. However, an increased rate of wound infections and comorbidities, mainly related to the symptom group of metabolic 
syndrome, are also possible explanations (25). In this context, alcohol consumption was a highly significant influence on the duration of inpatient residence that must be mentioned. The association with poorer postoperative outcomes with persistent alcohol consumption has been previously confirmed by several authors $(26,27)$. Patients with chronic alcohol consumption, in general, often experience muscular imbalance with reduced muscle strength, which could be a reason for a longer duration until convalescence is achieved. These factors, combined with the increased risk of bleeding and wound infections, may be responsible for prolonged inpatient stays (28).

For the patient-independent factors, transfusion and surgery time played significant roles in this study. Husted et al. have also clearly shown the effect of transfusion. The risk of a longer inpatient residence period after transfusion was even increased to four times higher than that of the comparison group (12). Spahn's review has also showed that perioperative anaemia levels not only lead to a longer hospital stay but also to increased risks of postoperative infections and poorer functional recovery (29). In the present investigation, prolonged surgery time increased the risk of longer inpatient residence time as has been confirmed by Foote et al. (16). The authors showed that, in particular, surgery time from a duration of two hours is associated with a longer inpatient stay, which has also been confirmed by Abbas et al. (21). In addition to an increased perioperative complication rate, the positive correlation with higher BMI values is usually revealed as a reason for a longer operation time (30).

In summary, patient-independent and patientspecific factors cannot be regarded as completely separate issues but as a summation, jointly dependent and independent, influencing the convalescence and thus the fast-track program.

The study is not free of limits. The retrospective approach must be considered as critical. The treatment protocol and the criteria associated with it were already established. All patients examined were treated according to the fast-track program of the University Hospital Halle. Since the exact treatment strategies for this principle are determined individually by each hospital, a comparison between the inpatient facilities is only possible to a limited extent. An additional limit is the restrictive selection of factors influencing the length of stay. For example, some studies consider the marital status, income associated with social status, psychological factors, surgical approach and cementation that all play a role for a longer hospitalization $(12,13)$.

A successful application of the fast-track program is evident and possible for every patient. However, for patients with increased risk profiles, longer inpatient stays and delayed discharges may be planned preoperatively, and the therapy concept can be further optimised in total hip arthroplasty. In addition, experienced surgeons should support the fast-track concept with an expeditious surgery time, which is associated with reduced blood loss and a low infection rate. Adequate preoperative preparation of the patient is indispensable.

\section{REFERENCES}

1. Wilmore DW. Recent advances: Management of patients in fast track surgery. BMJ. 2001; 322(7284): 473-6.

2. Schwenk W. Fast-Track-Rehabilitation in der Viszeralchirurgie. Chirurg. 2009; 80(8): 690-701.

3. Möllhoff T, Kress H-J, Tsompanidis K, Wolf C, Ploum P. Fast-Track-Rehabilitation am Beispiel der Kolonchirurgie: Beitrag der Anästhesie. Anaesthesist. 2007; 56(7): 713-28.

4. Bandholm T, Kehlet H. Physiotherapy Exercise After Fast-Track Total Hip and Knee Arthroplasty: Time for Reconsideration? Archives of Physical Medicine and Rehabilitation. 2012; 93(7): 1292-4.

5. Holm B, Thorborg K, Husted H, Kehlet H, Bandholm T. Surgery-Induced Changes and Early Recovery of Hip-Muscle Strength, Leg-Press Power, and Functional Performance after Fast-Track Total Hip Arthroplasty: A Prospective Cohort Study. PLoS ONE. 2013;8(4): e62109.

6. Glassou EN, Pedersen AB, Hansen TB. Risk of readmission, reoperation, and mortality within 90 days of total hip and knee arthroplasty in fast-track departments in Denmark from 2005 to 2011. Acta Orthop. 2014; 85(5):493500 .

7. Husted H, Otte KS, Kristensen BB, Ørsnes T, Kehlet H. Readmissions after fast-track hip and knee arthroplasty. Arch Orthop Trauma Surg. 2010; 130(9): 1185-91.

8. Bleß H-H, Kip M. Weißbuch Gelenkersatz: Versorgungssituation bei endoprothetischen Hüft- und Knieoperationen in Deutschland. Berlin, Heidelberg: Springer Berlin Heidelberg; 2017

9. Husted H, Holm G. Fast track in total hip and knee arthroplasty - experiences from Hvidovre University Hospital, Denmark. Injury. 2006; 37: 31-5. 
10. Khan SK, Malviya A, Muller SD, Carluke I, Partington PF, Emmerson KP. Reduced short-term complications and mortality following Enhanced Recovery primary hip and knee arthroplasty: results from 6,000 consecutive procedures. Acta Orthop. 2014; 85(1): 26-31.

11. Specht K, Kjaersgaard-Andersen P, Kehlet H, Wedderkopp N, Pedersen BD. High patient satisfaction in 445 patients who underwent fast-track hip or knee replacement. Acta Orthop. 2015; 86(6): 702-7.

12. Husted H, Holm G, Jacobsen S. Predictors of length of stay and patient satisfaction after hip and knee replacement surgery: Fast-track experience in 712 patients. Acta Orthop. 2008; 79(2): 168-73.

13. den Hartog YM, Mathijssen NMC, Hannink G, Vehmeijer SBW. Which patient characteristics influence length of hospital stay after primary total hip arthroplasty in a 'fast-track' setting? The Bone \& Joint Journal. 2015; 97-B(1): 19-23.

14. Jørgensen CC, Kehlet H. Role of patient characteristics for fast-track hip and knee arthroplasty. Brit J Anaesthesia. 2013; 110(6): 972-80.

15. Hayes JH, Cleary R, Gillespie WJ, Pinder IM, Sher JL. Are clinical and patient assessed outcomes affected by reducing length of hospital stay for total hip arthroplasty? $J$ Arthroplasty. 2000; 15(4): 448-52.

16. Foote J, Panchoo K, Blair P, Bannister G. Length of Stay Following Primary Total Hip Replacement. Annals. 2009; 91(6): 500-4.

17. Clement ND, MacDonald D, Howie CR, Biant LC. The outcome of primary total hip and knee arthroplasty in patients aged 80 years or more. The Journal of Bone and Joint Surgery British volume. 2011; 93-B(9): 1265-70.

18. McVeigh TP, Al-Azawi D, O'Donoghue GT, Kerin MJ. Assessing the impact of an ageing population on complication rates and in-patient length of stay. International Journal of Surgery. 2013; 11(9): 872-5.

19. Preston SD, Southall AR, Nel M, Das SK. Geriatric surgery is about disease, not age. $J$ R Soc Med. 2008; 101(8): 409-15.

20. Jämsen E, Puolakka T, Eskelinen A, Jäntti P, Kalliovalkama $\mathbf{J}$, Nieminen $\mathbf{J}$, et al. Predictors of mortality following primary hip and knee replacement in the aged: A single-center analysis of 1,998 primary hip and knee replacements for primary osteoarthritis. Acta Orthop. 2013; 84(1):44-53.

21. Abbas K, Umer M, Qadir I, Zaheer J, Rashid H. Predictors of Length of Hospital Stay after Total Hip Replacement. J Orthop Surg (Hong Kong). 2011; 19(3): 284-7.

22. Olthof M, Stevens M, Bulstra SK, van den AkkerScheek I. The association between comorbidity and length of hospital stay and costs in total hip arthroplasty patients: a systematic review. J Arthroplasty. 2014; 29(5): 1009-14.

23. Azodi OS, Bellocco R, Eriksson K, Adami J. The impact of tobacco use and body mass index on the length of stay in hospital and the risk of post-operative complications among patients undergoing total hip replacement. The Journal of Bone and Joint Surgery British volume. October 2006; 88B(10): 1316-20.

24. Haynes J, Nam D, Barrack RL. Obesity in total hip arthroplasty: does it make a difference? Bone Joint J. 2017; 99-B:31-6.

25. Namba RS, Paxton L, Fithian DC, Stone ML. Obesity and Perioperative Morbidity in Total Hip and Total Knee Arthroplasty Patients. J Arthroplasty. 2005; 20: 46-50.

26. Harris AH, Reeder R, Ellerbe L, Bradley KA, Rubinsky AD, Giori NJ. Preoperative Alcohol Screening Scores: Association with Complications in Men Undergoing Total Joint Arthroplasty: J Bone Joint Surg-Am. 2011; 93(4): 3217.

27. de Wit M, Goldberg S, Hussein E, Neifeld JP. Health Care-Associated Infections in Surgical Patients Undergoing Elective Surgery: Are Alcohol Use Disorders a Risk Factor? $J$ Am College Surg. 2012; 215(2): 229-36.

28. Tønnesen H, Nielsen PR, Lauritzen JB, Møller AM. Smoking and alcohol intervention before surgery: evidence for best practice. Br J Anaesthesia. 2009; 102(3): 297-306.

29. Spahn DR. Anemia and Patient Blood Management in Hip and Knee Surgery. Anesthesiology. 2010; 113(2): 482-95.

30. Perka C, Paul C, Matziolis G. Einflussfaktoren auf die perioperative Morbidität und Mortalität in der primären Hüftendoprothetik. Orthopäde. 2004; 33(6). 